\title{
Short communication: Efficacy of copper sulfate hoof baths against digital dermatitis-Where is the evidence?
}

\author{
Peter T. Thomsen ${ }^{1}$ \\ Department of Animal Science, Aarhus University, PO Box 50, DK-8830 Tjele, Denmark
}

\section{ABSTRACT}

Digital dermatitis is a major problem in modern dairy production because of decreased animal welfare and financial losses. Individual cow treatments are often seen as too time consuming by farmers, and walkthrough hoof baths have therefore been used extensively to control digital dermatitis. For decades, copper sulfate hoof baths have been used to treat and prevent digital dermatitis. Copper sulfate has been referred to as the industry gold standard when it comes to hoofbath chemicals. In several scientific studies testing the efficacy of other hoof-care products, copper sulfate has been used as a positive control, thereby indicating that copper sulfate has a known positive effect. However, this may not be the case. A dilemma may exist between (1) copper sulfate generally being perceived as being effective against digital dermatitis and (2) a possible lack of well-documented scientific evidence of this effect. The objective of this study was to evaluate the existing scientific literature to determine whether the efficacy of copper sulfate used in hoof baths against digital dermatitis has in fact been demonstrated scientifically. A systematic literature search identified 7 peer-reviewed journal articles describing the efficacy of copper sulfate in hoof baths as treatment or prevention of bovine digital dermatitis. Only 2 of the 7 studies compared copper sulfate to a negative control; most studies were relatively small, and often no clear positive effect of copper sulfate was demonstrated. In conclusion, the frequent claim that copper sulfate is widely reported to be effective is supported by little scientific evidence. Well-designed clinical trials evaluating the effect of copper sulfate against digital dermatitis compared with a negative control are needed. Until such studies have been made, the efficacy of copper sulfate in hoof baths against digital dermatitis remains largely unproven.

Key words: dairy cow, hoof bath, copper sulfate, digital dermatitis, evidence-based veterinary medicine

\footnotetext{
Received November 21, 2014.

Accepted December 12, 2014.

${ }^{1}$ Corresponding author: ptt@anis.au.dk
}

\section{Short Communication}

Digital dermatitis (DD) is a major problem in modern dairy production. Digital dermatitis is prevalent in many countries throughout the world (Rodriguez-Lainz et al., 1998; Holzhauer et al., 2006; Cramer at al., 2008; Thomsen et al., 2012) and causes financial losses due to, e.g., decreased milk production, excessive culling and extra work load, and compromised animal welfare due to discomfort and pain (Losinger, 2006; Bruijnis et al., 2010; Bruijnis et al., 2012). A case of DD has been estimated to have an average cost of $\$ 133$ (Cha et al., 2010) and cow-level prevalences of DD are often reported to be 20 to $25 \%$ (Holzhauer et al., 2006; Cramer at al., 2008; Thomsen et al., 2012). This means that DD has a major negative effect on the farmer's economy.

The precise etiology of DD is still not fully understood. However, bacteria of the genus Treponema are considered to play a vital role - possibly in combination with other bacteria (e.g., Dichelobacter nodosus) and predisposing environmental factors (e.g., maceration of the skin; Rasmussen et al., 2012). Disinfectants and antibiotics are therefore frequently used to treat DD, copper sulfate $\left(\mathrm{CuSO}_{4}\right)$ being one of these disinfectants (Laven and Logue, 2006). The antibacterial properties of copper have been known for a very long time, the first reports of using copper against several diseases being more than 3,000 yr old (Konieczny and Rdzawski, 2012). Hartshorn et al. (2013) demonstrated an in vitro effect of copper sulfate against a Treponema phagedenis-like isolate. They also found that the effectiveness of copper sulfate was severely hampered when manure was present. However, no in vivo testing was done to evaluate the effect of copper sulfate against DD in live cows.

Individual cow treatments are often seen as too time consuming by farmers (Leach et al., 2010; Relun et al., 2013a), and walk-through hoof baths have therefore been used extensively to control DD. Several different hoof-bath chemicals have been used in such hoof baths. For decades, copper sulfate has been one of the most popular compounds used in hoof baths (Laven and Logue, 2006; Cook et al., 2012; Relun et al., 2013a), and 
it has been stated that copper sulfate is widely reported to be effective (e.g., Logue et al., 2012). Based on its frequent use, copper sulfate has been referred to as the industry gold standard when it comes to hoof-bath chemicals (Teixeira et al., 2010; Smith et al., 2014). In several scientific studies testing the efficacy of other hoof-care products, copper sulfate has been used as a positive control, thereby indicating that copper sulfate has a known positive effect (Teixeira et al., 2010; Logue et al., 2012; Smith et al., 2014). However, this may not be the case. Several authors have stated that in general there is too much anecdotal evidence and a lack of controlled clinical trials when it comes to the treatment and prevention of lameness in general and the efficacy of hoof-care products used in hoof baths in particular (Hirst et al., 2002; Laven and Logue, 2006; Thomsen et al., 2008; Potterton et al., 2012).

The dilemma that may exist between (1) copper sulfate generally being perceived as being effective against DD and (2) a possible lack of scientific evidence of this effect will be evaluated in this paper. The objective was to evaluate the existing scientific literature to determine whether the efficacy of copper sulfate used in hoof baths against DD has in fact been demonstrated and described in well-documented, peer-reviewed scientific journal articles.

A systematic literature search was conducted in September 2014 to identify relevant peer-reviewed scientific journal articles describing the efficacy of copper sulfate in hoof baths as treatment or prevention of DD. To maximize the chance of finding all relevant literature, the literature search was performed using the databases Web of Science, CAB Abstracts, and Scopus, based on the recommendations from Grindlay et al. (2012). The searches were based on the key words (hoof bath* or hoofbath* or foot bath* or footbath*) and (copper sulfate or coppersulfate or copper sulphate or coppersulphate or $\left.\mathrm{CuSO}^{*}\right)$. The search was not restricted to any species (e.g., cow) or disease (digital dermatitis) in order not to exclude any potentially relevant papers. The key words were searched in the title, abstract, or key words of articles. Peer-reviewed journal articles were included in the list of relevant literature irrespective of the year of publication. Only articles in English were considered. In addition to the systematic literature search, references in the identified articles were also scrutinized to find relevant literature, and all articles citing the identified articles were checked for relevance. All papers found during the literature search were scrutinized to check the relevance for the objective of this study, and papers not describing evaluations of the efficacy of copper sulfate in hoof baths against bovine DD were not considered further.
The literature search using Web of Science resulted in 29 papers (of which 25 were peer-reviewed articles) with information about hoof baths and copper sulfate, the search using $\mathrm{CAB}$ Abstracts resulted in 75 papers (25 peer-reviewed articles), and the search using Scopus resulted in 12 papers (8 peer-reviewed articles). Manual scrutiny of all identified papers showed that only 7 of these papers were peer-reviewed journal articles describing some kind of evaluation of the efficacy of copper sulfate in hoof baths against bovine DD. Other papers were either non-peer-reviewed articles, conference papers, or peer-reviewed scientific articles dealing with, for example, residues of hoof-care products in milk, effects of copper sulfate on plant growth, evaluation of other hoof-care products than copper sulfate, or copper-based foot baths for treatment of ovine footrot.

Information about the 7 relevant peer-reviewed articles is summarized in Table 1. Laven and Hunt (2002) evaluated the efficacy of 4 hoof-care products. Four groups of cows in an experimental herd were treated with erythromycin, formalin, copper sulfate, or peracetic acid. All 4 treatments resulted in a decreased lesion score with time. Copper sulfate was as good as the other treatments but was not compared with a negative control. Speijers et al. (2010) compared 37 cows hoof bathed with copper sulfate with 39 control cows and found more cows with no DD lesions, less cows with active DD lesions, and more cows with chronic lesions in the treatment group. They found no effect of copper sulfate on the prevention of DD. Severe cases of DD were treated topically with antibiotics, and the possible effect of this on the prevalence of DD in the treatment and control group was not very well described in the article. Teixeira et al. (2010) used copper sulfate as a positive control when testing a commercial hoof-care product. They found no differences between the 2 treatments, and the prevalence of DD remained virtually unchanged throughout the study period irrespective of the product used. Logue et al. (2012) used copper sulfate as a positive control when testing a commercial hoof-care product. Both products were found to reduce the severity of DD lesion scores, and feet treated with copper sulfate were approximately 1.5 times more likely to improve compared with feet treated with the commercial product. However, this effect was only seen in 1 of 3 possible combinations of DD lesion scorings. Speijers et al. (2012) evaluated the effect of different hoof-bathing frequencies and found that more frequent use of copper sulfate hoof baths resulted in more cows without DD lesions. Also in this study severe cases of DD were treated topically with antibiotics. As part of a larger study on treatment strategies for infectious hoof disorders, Fjeldaas et al. (2014) evaluated the effect 
of copper sulfate hoof baths on DD. They compared 22 cows walking through a copper sulfate hoof bath with a control group of 18 cows. However, no cows in either the treatment or the control group had DD at the start or end of the study period. It was, therefore, not possible to draw any conclusions regarding the efficacy of copper sulfate against DD based on their study. Smith et al. (2014) used copper sulfate as a positive control when testing a commercial hoof-care product. They concluded that copper sulfate and the commercial hoof-care product were equally good, but no negative control was included in the study.

Only 2 of the 7 studies in Table 1 compared copper sulfate to a negative control (Speijers et al., 2010; Fjeldaas et al., 2014). However, in the study by Fjeldaas et al. (2014) no cows had DD either before or after the treatment. The effect of copper sulfate on prevalence, prevention, or cure of DD could, therefore, not be assessed. The lack of a negative control in most studies means that it is very difficult to evaluate the efficacy of copper sulfate. Copper sulfate being as good as some other products (Laven and Hunt, 2002; Teixeira et al., 2010; Smith et al., 2014) could mean that both or all products were equally effective against $\mathrm{DD}$, or it could mean that none of the products had any effect. A controlled clinical trial with a negative control is, therefore, needed to effectively evaluate the efficacy of copper sulfate. The only 2 studies with a negative control included very few cows: 37 cows treated and 39 control (Speijers et al., 2010) and 22 treated and 18 control (Fjeldaas et al., 2014).

In many cases copper sulfate was used as a positive control in a study where the primary objective was to evaluate the effect of another (new) hoof-care product (Laven and Hunt, 2002; Teixeira et al., 2010; Logue et al., 2012; Smith et al., 2014). Thus, an evaluation of the efficacy of copper sulfate was not the primary objective of the studies. Additionally, in some studies the evaluation of the efficacy of copper sulfate was only a minor part of a larger study. Fjeldaas et al. (2014) evaluated 4 different control strategies against DD, interdigital dermatitis, and heel-horn erosions. A hoof bath with copper sulfate was just one of these strategies. Laven and Hunt (2002) tested the efficacy of 4 different hoofcare products, one of them being copper sulfate. Only the study of Speijers et al. (2010) had an evaluation of the efficacy of copper sulfate (and hypochlorite) as the primary objective. In a follow-up study the same group later evaluated the effect of different treatment frequencies (Speijers et al., 2012).

The spontaneous cure of DD has been shown to be high. Relun et al. (2012), e.g., found a spontaneous monthly cure rate of untreated DD lesions of $61 \%$. In the absence of an untreated control group, a decrease in the prevalence of DD over time in a group of cows treated with copper sulfate (as seen, e.g., in Smith et al., 2014) may, therefore, not necessarily be indicative of copper sulfate being effective against DD. It may well be that the prevalence of DD would have decreased equally without any treatment. Teixeira et al. (2010) stated that copper sulfate was as good as a commercial hoof-care product, but the prevalence of DD remained virtually unchanged in both groups throughout the study (DD prevalence of 26,22 , and $31 \%$ in wk 0,2 , and 4 in the copper sulfate group).

Several studies identified in the initial literature search were not included in Table 1 for various reasons; some studies did not use copper sulfate but various commercial products containing copper (often an unspecified amount and form of copper in addition to several other potentially active components). Manske et al. (2002) and Holzhauer et al. (2012) used 2 different commercial hoof-care products containing acidified ionized copper, and Relun et al. (2012, 2013b) used a hoof-care product containing copper and zinc chelates. The choice of only including peer-reviewed journal articles in the present study was an attempt to ensure a certain level of quality of the studies included. This may, however, mean that evaluations of copper sulfate published in other forms may have been missed.

Sample sizes were generally low in all studies included in Table 1. Five of the seven studies included only one herd, and the number of cows per study ranged from 40 to 408 . None of the studies presented any samplesize calculations, and the statistical power may, in some cases, have been inadequate.

It is well known that the probability of publication is higher for positive results (demonstrating an effect of a treatment) compared with negative results (demonstrating no effect; e.g., Dickersin et al., 1987; Vawdrey and Hripcsak, 2013). Such publication bias could have meant that studies demonstrating no positive effect of copper sulfate would have been less likely to become published compared with studies demonstrating a positive effect of copper sulfate. Still, the number of publications demonstrating some kind of positive effect of copper sulfate is very low.

In evidence-based (veterinary) medicine, several different levels of evidence are often described. Evidence levels typically range from (reviews or meta-analysis of) randomized, controlled clinical trials with a negative control to undocumented (clinical) experience of individuals or groups of people (Cockcroft and Holmes, 2003). A low level of evidence does not necessarily mean that a certain treatment is not effective, but caution needs to be taken when interpreting such evidence. Additionally, when communicating with, e.g., farmers, it is important to underscore the limitations of the 
Table 1. Summary of 7 studies evaluating the efficacy of copper sulfate in hoof baths against digital dermatitis (DD)

$\mathrm{CuSO}_{4} \quad$ Year

Comments,

\begin{tabular}{|c|c|c|c|c|c|c|}
\hline Study & $\begin{array}{c}\text { concentration } \\
(\%)\end{array}$ & Country & $\begin{array}{l}\text { of } \\
\text { study }\end{array}$ & $\begin{array}{l}\text { Animals } \\
\text { used }\end{array}$ & Study design & $\begin{array}{l}\text { Negative } \\
\text { control }\end{array}$ \\
\hline
\end{tabular}

Laven and Hunt, $2002 \quad 2 \quad$ UK $2000 \quad 169$

169 cows/1 Cows divided into 4 groups

experimental treated with erythromycin $(52$ herd

cows), formalin (42), copper sulfate (31), or peracetic acid
(44). Scoring of DD on d $0,4,7$ and 21 .

Speijers et al., $2010 \quad 2$ and $5 \quad$ UK

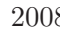

76 cows/1 2 groups: copper sulfate $(37$ cows) Yes experimental and no hoof bath (39 cows). DD herd scorings every week for 5 wk.

Teixeira et al., 2010 10

\section{$2009 \quad 356$ cows $/ 1$} herd

\section{Logue et al., 2012} UK $\begin{array}{ll}\text { Not } & 408 \text { cows } / 6 \\ \text { stated } & \text { commercial }\end{array}$ herds

Test of commercial hoof-care product against copper sulfate as a positive control using a split hoof bath. Scoring of DD on d 0 and around d 50 and 110 . product (used in 2 pens, 167 cows) against copper sulfate as positive control (used in 2 other pens, 189 cows). DD scoring on wk 0,2 , and 4 .

Main results

interpretation

limitations

No

All treatments resulted in a decreased lesion score with time. The decrease in lesion scores was not different for the compared with a negative 4 treatments. control.

Significantly more cows with no DD lesions in copper

sulfate-treated cows compared with control cows ( 45 vs. $30 \%$ ) Fewer active DD lesions and more chronic lesions in treate cows. No effect of copper sulfate on prevention of DD.

$5 \%$ copper sulfate was found to result in significantly more cows with no DD lesions compared with $2 \%$ coppe sulfate. Severe cases of

with antibiotics.

No significant difference in prevalence of $\mathrm{DD}$, new DD lesions, or cure of DD between groups treated with copper sulfate and commercial product. No overal change in DD prevalence in copper sulfate-treated cows throughout the study.

\section{Copper sulfate was "as} good as" a commercial product, but the prevalence of DD remained virtually unchanged in both group throughout the study (DD prevalence of 26 , 22 , and $31 \%$ in wk 0,2 , and 4 in copper sulfate group).

Both products reduced the severity of DD scores. Feet treated with copper sulfate were 1.5 times more likely to improve.

The higher odds of improvement for copper sulfate-treated feet was only seen when comparing scorings 1 and 3 , not when comparing scorings 1 and 2 or 2 and 3 .

Significantly more cows with no DD lesions in the weekly (48\%) compared with the every-second-week (24\%) hoofno DD lesions in the everysecond-week (80\%) compared with the monthly $(65 \%)$ hoofbathing group.
Severe cases of DD were treated topically with antibiotics. 
existing evidence. Few peer-reviewed journal articles demonstrating efficacy of copper sulfate against DD, thus, does not necessarily mean that copper sulfate is not effective against DD but rather means that the efficacy of copper sulfate is not well documented - at least at the moment.

In conclusion, the frequent claim that copper sulfate is widely reported to be effective is supported by little scientific evidence. Given the very high prevalence of DD in many countries, the large economic and welfare consequences of the disease, and the frequent use of copper sulfate in hoof baths, the number of peerreviewed articles evaluating the efficacy of copper sulfate is surprisingly low. Only one peer-reviewed article found a positive effect of copper sulfate compared with a negative control. Additionally, most published studies are relatively small, do not include a negative control group, and often no clear positive effect of copper sulfate is demonstrated. This means that welldesigned clinical trials evaluating the effect of copper sulfate against DD compared with a negative control are needed. Until such studies have been conducted, the efficacy of copper sulfate in hoof baths against DD remains largely unproven.

\section{ACKNOWLEDGMENTS}

The author thanks Hans Houe, University of Copenhagen, and Jan Tind Sørensen, Aarhus University, for useful comments.

\section{REFERENCES}

Bruijnis, M. R. N., B. Beerda, H. Hogeveen, and E. N. Stassen. 2012. Assessing the welfare impact of foot disorders in dairy cattle by a modeling approach. Animal 6:962-970.

Bruijnis, M. R. N., H. Hogeveen, and E. N. Stassen. 2010. Assessing economic consequences of foot disorders in dairy cattle using a dynamic stochastic simulation model. J. Dairy Sci. 93:2419-2432.

Cha, E., J. A. Hertl, D. Bar, and Y. T. Gröhn. 2010. The cost of different types of lameness in dairy cows calculated by dynamic programming. Prev. Vet. Med. 97:1-8.

Cockcroft, P., and M. Holmes. 2003. Handbook of Evidence-Based Veterinary Medicine. Blackwell Publ., Oxford, UK.

Cook, N. B., J. Reiman, A. Gomez, and K. Burgi. 2012. Observations on the design and use of footbaths for the control of infectious hoof disease in dairy cattle. Vet. J. 193:669-673.

Cramer, G., K. D. Lissemore, C. L. Guard, K. E. Leslie, and D. F. Kelton. 2008. Herd- and cow-level prevalence of foot lesions in Ontario dairy cattle. J. Dairy Sci. 91:3888-3895.

Dickersin, K., S. Chan, T. C. Chalmers, H. S. Sachs, and H. Smith Jr. 1987. Publication bias and clinical trials. Control. Clin. Trials 8:343-353.

Fjeldaas, T., M. Knappe-Poindecker, K. E. Bøe, and R. B. Larssen. 2014. Water footbath, automatic flushing, and disinfection to improve the health of bovine feet. J. Dairy Sci. 97:2835-2846.

Grindlay, D. J. C., M. L. Brennan, and R. S. Dean. 2012. Searching the veterinary literature: A comparison of the coverage of veterinary journals by nine bibliographic databases. J. Vet. Med. Educ. 39:404-412.

Hartshorn, R. E., E. C. Thomas, K. Anklam, M. G. Lopez-Benavides, M. Buchalova, T. C. Hemling, and D. Döpfer. 2013. Short com- 
munication: Minimum bactericidal concentration of disinfectants evaluated for bovine digital dermatitis-associated Treponema phagedenis-like spirochetes. J. Dairy Sci. 96:3034-3038.

Hirst, W. M., A. M. Le Fevre, D. N. Logue, J. E. Offer, S. J. Chaplin, R. D. Murray, W. R. Ward, and N. P. French. 2002. A systematic compilation and classification of the literature on lameness in cattle. Vet. J. 164:7-19.

Holzhauer, M., C. J. Bartels, C. Bergsten, M. M. J. van Riet, K. Frankena, and T. J. G. M. Lam. 2012. The effect of an acidified, ionized copper sulphate solution on digital dermatitis in dairy cows. Vet. J. 193:659-663.

Holzhauer, M., C. Hardenberg, C. J. M. Bartels, and K. Frankena. 2006. Herd- and cow-level prevalence of digital dermatitis in The Netherlands and associated risk factors. J. Dairy Sci. 89:580-588.

Konieczny, J., and Z. Rdzawski. 2012. Antibacterial properties of copper and its alloys. Arch. Mat. Sci. Eng. 56:53-60.

Laven, R. A., and H. Hunt. 2002. Evaluation of copper sulphate, formalin and peracetic acid in footbaths for the treatment of digital dermatitis in cattle. Vet. Rec. 151:144-146.

Laven, R. A., and D. N. Logue. 2006. Treatment strategies for digital dermatitis for the UK. Vet. J. 171:79-88.

Leach, K. A., H. R. Whay, C. M. Maggs, Z. E. Barker, E. S. Paul, A K. Bell, and D. C. J. Main. 2010. Working towards a reduction in cattle lameness: 1 . Understanding barriers to lameness control on dairy farms. Res. Vet. Sci. 89:311-317.

Logue, D. N., T. Gibert, T. Parkin, S. Thomson, and D. J. Taylor. 2012. A field evaluation of a footbathing solution for the control of digital dermatitis in cattle. Vet. J. 193:664-668.

Losinger, W. C. 2006. Economic impacts of reduced milk production associated with papillomatous digital dermatitis in dairy cows in the USA. J. Dairy Res. 73:244-256.

Manske, T., J. Hultgren, and C. Bergsten. 2002. Topical treatment of digital dermatitis associated with severe heel-horn erosion in a Swedish dairy herd. Prev. Vet. Med. 53:215-231.

Potterton, S. L., N. J. Bell, H. R. Whay, E. A. Berry, O. C. D. Atkinson, R. S. Dean, D. C. J. Main, and J. N. Huxley. 2012. A descriptive review of the peer and non-peer reviewed literature on the treatment and prevention of foot lameness in cattle published between 2000 and 2011. Vet. J. 193:612-616.

Rasmussen, M., N. Capion, K. Klitgaard, T. Rogdo, T. Fjelaas, M. Boye, and T. K. Jensen. 2012. Bovine digital dermatitis: Possible pathogenic consortium consisting of Dichelobacter nodosus and multiple Treponema species. Vet. Microbiol. 160:151-161.

Relun, A., R. Guatteo, M. M. Auzanneau, and N. Bareille. 2013a. Farmers' practices, motivators and barriers for adoption of treatments of digital dermatitis in dairy farms. Animal 7:1542-1550.

Relun, A., A. Lehebel, N. Bareille, and R. Guatteo. 2012. Effectiveness of different regimens of a collective topical treatment using a solution of copper and zinc chelates in the cure of digital dermatitis in dairy farms under field conditions. J. Dairy Sci. 95:3722-3735.

Relun, A., A. Lehebel, M. Bruggink, N. Bareille, and R. Guatteo. 2013b. Estimation of the relative impact of treatment and herd management practices on prevention of digital dermatitis in French dairy herds. Prev. Vet. Med. 110:558-562.

Rodriguez-Lainz, A., P. Melendez-Retamal, D. W. Hird, and D. H. Read. 1998. Papillomatous digital dermatitis in Chilean dairies and evaluation of a screening method. Prev. Vet. Med. 37:197207.

Smith, A. C., C. L. Wood, K. J. McQuerry, and J. M. Bewley. 2014 Effect of a tea tree oil and organic acid footbath solution on digital dermatitis in dairy cows. J. Dairy Sci. 97:2498-2501.

Speijers, M. H. M., L. G. Baird, G. A. Finney, J. McBride, D. J. Kilpatrick, D. N. Logue, and N. E. O'Connell. 2010. Effectiveness of different footbath solutions in the treatment of digital dermatitis in dairy cows. J. Dairy Sci. 93:5782-5791.

Speijers, M. H. M., G. A. Finney, J. McBride, S. Watson, D. N. Logue, and N. E. O'Connell. 2012. Effectiveness of different footbathing frequencies using copper sulfate in the control of digital dermatitis in dairy cows. J. Dairy Sci. 95:2955-2964.

Teixeira, A. G. V., V. S. Machado, L. S. Caixeta, V. Pereira, and R. C. Bicalho. 2010. Efficacy of formalin, coper sulfate, and a commercial footbath product in the control of digital dermatitis. J. Dairy Sci. 93:3628-3634.

Thomsen, P. T., L. Munksgaard, and J. T. Sørensen. 2012. Locomotion scores and lying behaviour are indicators of hoof lesions in dairy cows. Vet. J. 193:644-647.

Thomsen, P. T., J. T. Sørensen, and A. K. Ersbøll. 2008. Evaluation of three commercial hoof-care products used in footbaths in Danish dairy herds. J. Dairy Sci. 91:1361-1365.

Vawdrey, D. K., and G. Hripcsak. 2013. Publication bias in clinical trials of electronic health records. J. Biomed. Inform. 46:139-141. 